\title{
MORC2 regulates C/EBPa-mediated cell differentiation via sumoylation
}

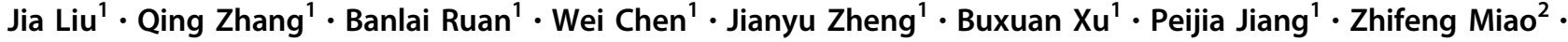 \\ Feng $\mathrm{Li}^{1} \cdot$ Jessie Yanxiang Guo ${ }^{3} \cdot \mathrm{Liu} \mathrm{Cao}^{1} \cdot$ Guiling Wang ${ }^{1}$
}

Received: 22 March 2018 / Revised: 25 November 2018 / Accepted: 28 November 2018 / Published online: 15 January 2019

(c) The Author(s) 2019. This article is published with open access

\begin{abstract}
The expression and activity of CCAAT/enhancer-binding protein $\alpha(\mathrm{C} / \mathrm{EBP} \alpha)$ are involved in sumoylation modification, which is critical to divert normal cells from differentiation to proliferation. However, the role and underlying mechanism of $\mathrm{C} / \mathrm{EBP} \alpha$ in cancer is poorly understood. Human MORC2 (microrchidia family CW-type zinc-finger 2), is a member of the MORC proteins family containing a CW-type zinc-finger domain. Here, we found that MORC2 interacted with TE-III domain of $\mathrm{C} / \mathrm{EBP} \alpha$, and the overexpression of MORC2 promoted wild-type C/EBP $\alpha$ sumoylation and its subsequent degradation, which didn't significantly observe in mutant C/EBP $\alpha-K 161$ R. Furthermore, the overexpression of MORC2 inhibited C/EBP $\alpha$-mediated $\mathrm{C} 2 \mathrm{C} 12$ cell differentiation to maintain cell cycle progression. Moreover, the striking correlation between the decreased $\mathrm{C} / \mathrm{EBP} \alpha$ expression and the increased MORC2 expression was also observed in the poor differentiation status of gastric cancer tissues. Most notably, the high expression of MORC2 is correlated with an aggressive phenotype of clinical gastric cancer and shorter overall survival of patients. Taken together, our findings demonstrated that MORC2 expression regulated C/EBP $\alpha$-mediated the axis of differentiation/proliferation via sumoylation modification, and affected its protein stability, causing cell proliferation and tumorigenesis.
\end{abstract}

\section{Introduction}

The tumorigenesis is a multistep process with numerous changes in cell proliferation, differentiation, and/or survival [1]. The molecular alterations that occurs during this

These authors contributed equally: Jia Liu, Qing Zhang

Edited by D. Aberdam

Supplementary information The online version of this article (https:// doi.org/10.1038/s41418-018-0259-4) contains supplementary material, which is available to authorized users.

Guiling Wang

glingwang@cmu.edu.cn

1 Department of Cell Biology, Key Laboratory of Cell Biology, Ministry of Public Health and Key Laboratory of Medical Cell Biology, Ministry of Education, China Medical University, Shenyang 110122, China

2 Department of Surgical Oncology and General Surgery, First Hospital of China Medical University, Shenyang 110001, China

3 Division of Medical Oncology, Rutgers Cancer Institute of New Jersey, New Brunswick, NJ 08903, USA progression include the over-expression and/or amplification of transcription factors, growth factors, and their receptors, or the silencing of tumor suppressive gene. CCAAT/enhancer-binding proteins (C/EBPs) are one such group of transcription factors that control cellular proliferation and differentiation in a variety of tissues [2, 3], which are involved in a variety of different cell process including physiology and pathology.

The $\mathrm{C} / \mathrm{EBP} \alpha$ is a founding member of the C/EBP proteins family, containing a highly conserved transactivation domain (TE-I, TE-II, and TE-III) and a basic leucine zipper (bZip) domain [4]. Given evidence suggests that transcription factors are modification by SUMO [5], which affects protein-protein interactions [6], sub-cellular localization [7], transcriptional activity [8], and protein stability [5]. Modification of C/EBP $\alpha$ by SUMO-1 at lysine reside 161 lies within the TE-III domain, which enables binding to specific proteins to affect its level of the sumoylation [8-10]. In addition, sumoylation and ubiquitin are conjugated either sequentially or simultaneously to functionally regulate the substrate protein in many cases [5, 11]. Sumoylation is oftentimes deregulated in cancer, and the sumoylation of $\mathrm{C} /$ EBP $\alpha$ decreases the tumor suppressive activity [10, 12], 
which is associated with various human cancers [3, 13, 14], suggesting that loss of $\mathrm{C} / \mathrm{EBP} \alpha$ might be associated with the switch from a cell differentiation to a cell proliferation program in cancer [15], but the mechanism of the downregulation of $\mathrm{C} / \mathrm{EBP} \alpha$ in cancer remains elusive.

Human MORC2 (microrchidia family $\mathrm{CW}$-type zincfinger 2), containing a CW-type zinc-finger and three coiled-coil domains, is a member of the MORC proteins family and mainly localizes in the nucleus [16, 17]. Recent studies revealed that MORC2 repressed gene transcription $[17,18]$ promoted chromatin remodeling during the DNAdamage response [18] and regulated lipogenesis [19]. Our research indicated that MORC2 promoted gastric cancer cell proliferation and tumorigenesis [20, 21].

Here, we found that MORC2 interacted with TE-III domain of $\mathrm{C} / \mathrm{EBP} \alpha$,which be related to the sumoylation of $\mathrm{C} / \mathrm{EBP} \alpha$. Moreover, the increased MORC2 expression negatively correlates with the decreased $\mathrm{C} / \mathrm{EBP} \alpha$, which was also shown in the differentiation status of gastric cancer samples. These results open a new line of study on the underlying mechanism of down-regulated $\mathrm{C} / \mathrm{EBP} \alpha$ expression in cancer, and identify that MORC2 plays an important role in control C/EBP $\alpha$-mediated the axis of differentiation/proliferation, which is involved in tumorigenesis.

\section{Results}

\section{MORC2 interacts with TE-III domain of C/EBPa}

An assay using GST-MORC2 and in vitro translated C/ EBP $\alpha$ demonstrated specific interaction between these two proteins (Fig. 1a). To further confirm MORC2 interacting with $\mathrm{C} / \mathrm{EBP} \alpha$ in vivo, a reciprocal co-immunoprecipitation assay was performed. As can be seen in Fig. 1b-d, C/EBP $\alpha$ was co-precipitated with MORC2 in vivo, suggesting that $\mathrm{C} / \mathrm{EBP} \alpha$ was specifically interacted with MORC2. A series of purified GST-fused C/EBP $\alpha$ proteins corresponding to the truncation and deletion constructs were performed by GST pull-down assays, and indicated that in vitro-translated MORC2 bound to the full length GST-C/EBP $\alpha$, GST-C1,

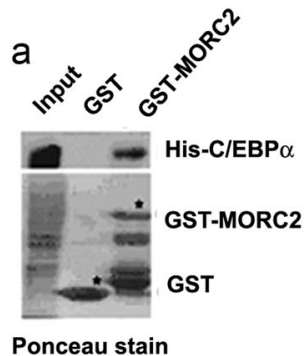

b

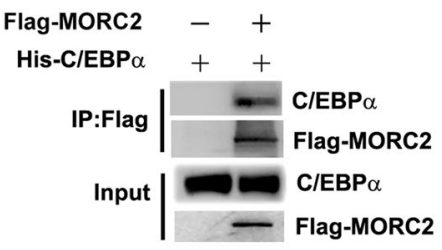

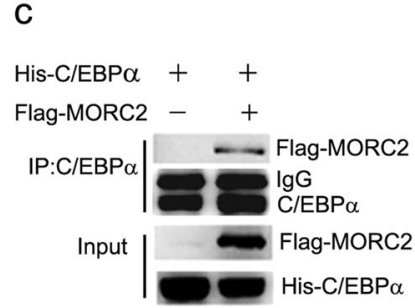
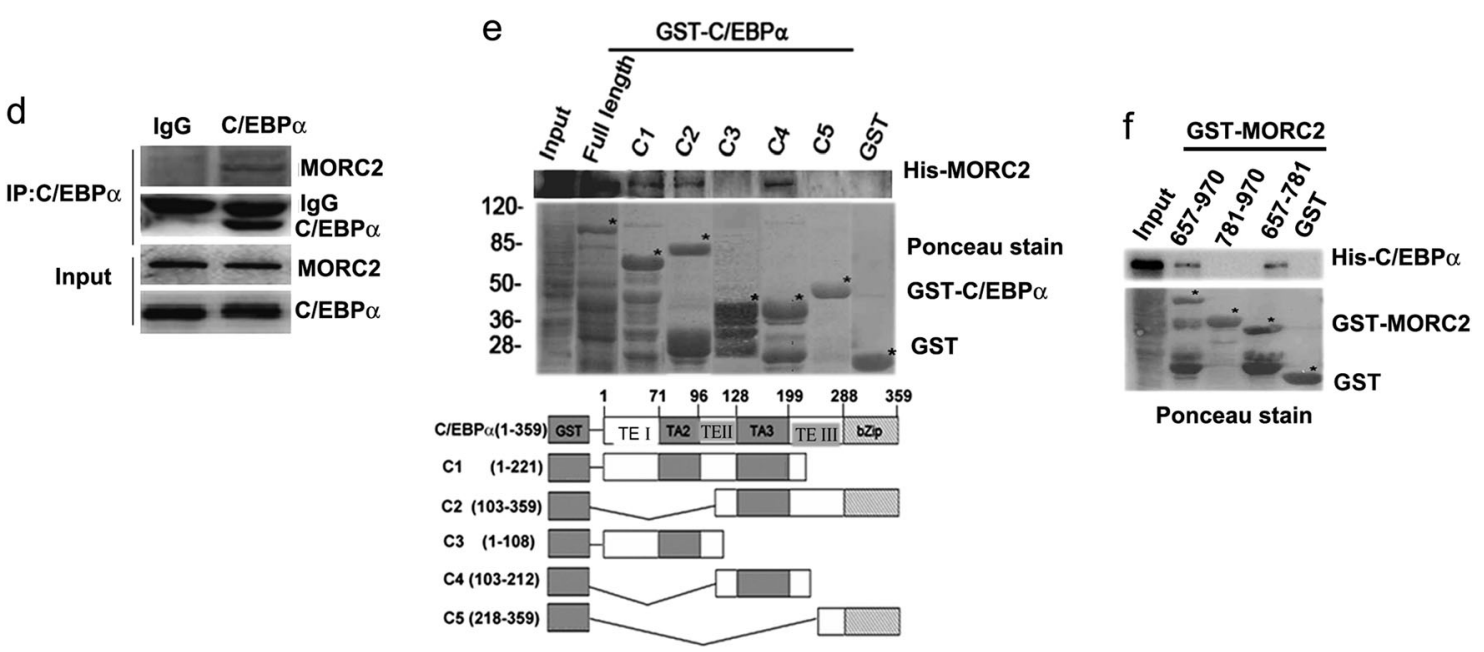

Fig. 1 MORC2 interacts with TE-III domain of C/EBP $\alpha$. a MORC2 directly binds $\mathrm{C} / \mathrm{EBP} \alpha$ in vitro. In vitro-transcribed and translated HisC/EBP $\alpha$ were incubated with either GST-MORC2 or GST. Bound proteins were analyzed by western blot with His-tag antibody. Black stars indicated the GST or GST-MORC2. b, c MORC2 interacts with $\mathrm{C} / \mathrm{EBP} \alpha$ in co-IP assay. HEK-293T cells were transiently transfected with His-C/EBP $\alpha$ plus Flag-MORC2 plasmids for $36 \mathrm{~h}$, as indicated. Total lysates were subjected to immunoprecipitate and Western Blot

with Flag-tagged or His-tagged antibody, as indicated. d The interaction between endogenous $\mathrm{C} / \mathrm{EBP} \alpha$ and MORC 2 was examined by IP assay in vivo. e, $\mathbf{f}$ Mapping of binding domains in $\mathrm{C} / \mathrm{EBP} \alpha$ and MORC2. For GST pull-down assay, GST, GST-C/EBP $\alpha$ or GSTMORC2 deletions were incubated with indicated proteins transcripted and translated in vitro. Bound proteins were detected with indicated antibodies. Black stars indicated the GST-fusion proteins 
GST-C2, GST-C4 but not GST-C3, GST-C5 or GST alone, showing that in vitro-translated MORC2 could bind to the GST-C4 (103-212) of $\mathrm{C} / \mathrm{EBP} \alpha$ (Fig. 1e), which is within TE-III domain [4]. Vice versa, in vitro-translated $\mathrm{C} / \mathrm{EBP} \alpha$ protein specifically binds to amino acids $657-781$ of GST-MORC2 (Figure 1f). Taken together, these data indicate that MORC2 specifically binds to TE-III domain of $\mathrm{C} / \mathrm{EBP} \alpha$.

\section{MORC2 negatively regulates C/EBPa expression}

In order to examine whether MORC2 regulates the expression of $\mathrm{C} / \mathrm{EBP} \alpha$, we transfected with His-MORC2 in the SGC7901 cells and found that the mRNA and protein levels of $\mathrm{C} /$ $\mathrm{EBP} \alpha$ were reduced with the increased ecotopic MORC2 expression (Fig. 2a, b). Whereas, specific knockdown of MORC2 up-regulated the mRNA and protein level of $\mathrm{C} /$ $\mathrm{EBP} \alpha$ (Fig. 2c, d) through targeting siRNA MORC2 or nonsilencing control in the BGC-823 cells. In addition, we got the similar results with overexpressing of MORC2 in SGC-7901 cells or knock down of MORC2 in BGC-823 cells (supplementary Figure1a and 1b). Together, these results indicate that MORC2 can specifically represses $\mathrm{C}$ / $\mathrm{EBP} \alpha$ expression.

In addition, immunofluorescence assays found that MORC2 co-localized with $\mathrm{C} / \mathrm{EBP} \alpha$ in the nucleus when MORC2 expression was normal (Fig. 2e, upper panel). Interestingly, the nuclear localization of $\mathrm{C} / \mathrm{EBP} \alpha$ was less when MORC2 was overexpressed (Fig. 2e, second lane in the lower panel), the co-localization of $\mathrm{C} / \mathrm{EBP} \alpha$ and MORC2 was mainly seen in nuclear membrane (Fig. 2e, last lane in the lower panel). Therefore, overexpression of MORC 2 may lead to the decreased nuclear localization of $\mathrm{C} / \mathrm{EBP} \alpha$, which may be related to the sumoylation of $\mathrm{C} / \mathrm{EBP} \alpha$.

\section{MORC2 overexpression promotes the sumoylation of $C / E B P a$ and its subsequent degradation}

The above results indicated that MORC2 interacted with TE-III domain of $\mathrm{C} / \mathrm{EBP} \alpha$, which overlaps with the SUMO1 conjugation lysine residue 161 site [4]. Thus, we tried to elucidate whether the reduction of $\mathrm{C} / \mathrm{EBP} \alpha$ by MORC 2 was related to its sumoylation. To test this postulation, we cotransfected His-C/EBP $\alpha$, T7-SUMO-1 and Flag-MORC2 into HEK-293T cells (which lacks endogenous $\mathrm{C} / \mathrm{EBP} \alpha$ ) and showed that the level of sumoylated $\mathrm{C} / \mathrm{EBP} \alpha$ was enhanced (Fig. 3a). The deficient sumoylation mutant vector of His-C/EBP $\alpha-\mathrm{K} 161 \mathrm{R}$ was constructed to further study the effect of MORC2 on the sumoylation of $\mathrm{C} / \mathrm{EBP} \alpha$ (Fig. 3b). As can be seen in Fig. 3c, the sumoylation of $\mathrm{C} / \mathrm{EBP} \alpha$ at $\mathrm{K} 161$ was enhanced when MORC2 was coexpressed (Fig. 3c, second lane, column 3 compared to column 1), while no sumoylation of $\mathrm{C} / \mathrm{EBP} \alpha$ was detected when MORC2 was co-transfected with the SUMO-deficient mutant of $\mathrm{C} / \mathrm{EBP} \alpha-\mathrm{K} 161 \mathrm{R}$ (Fig. 3c, column 4 of second lane). a

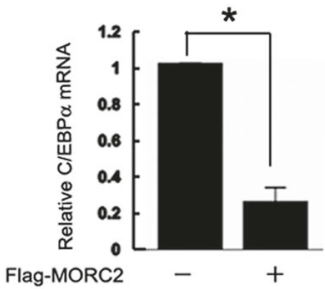

b

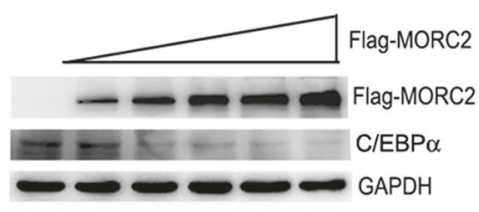

C

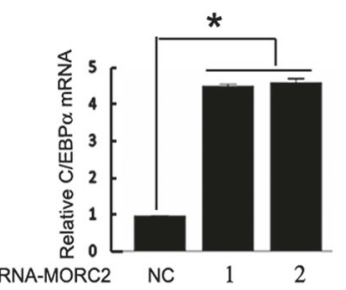

e

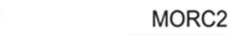

His-MORC2 d

Con 122 siRNA MORC2

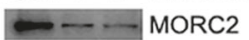

$\longrightarrow$ C/EBP $\alpha$

$\longrightarrow$ GAPDH

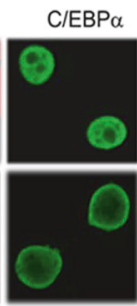

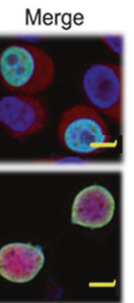

Fig. 2 MORC2 negatively regulates $\mathrm{C} / \mathrm{EBP} \alpha$ expression. a, b The mRNA and protein levels of $\mathrm{C} / \mathrm{EBP} \alpha$ were reduced by the enhancing ecotopic MORC2 expression. A dose dependent increase of MORC2 plasmids were transfected into SGC-7901 cells. QPCR and Western blot assays were performed to detect the mRNA and protein levels of endogenous C/EBP $\alpha$. c, d Knockdown of MORC2 can increase the mRNA and protein levels of C/EBP $\alpha$. BGC-823 cells were transfected with siRNAs targeting MORC2 or non-silencing control. After $30 \mathrm{~h}$ of transfection, the mRNA and protein levels of $\mathrm{C} / \mathrm{EBP} \alpha$ were measured by qPCR and western blotting assays. (e) Co-localization of C/EBP $\alpha$ and MORC2 was observed by confocal microscopy. SGC-7901 cells were transfected with His-C/EBP $\alpha$ along with pcDNA3.1-vector or pcDNA3.1-MORC2 and performed immunofluorescence assays with specific MORC 2 and $\mathrm{C} / \mathrm{EBP} \alpha$ antibodies. Alexa Fluor 488(Green) and Alexa Fluor 546 (red) were used to detect $\mathrm{C} / \mathrm{EBP} \alpha$ (green) and MORC2 (red) respectively. Yellow indicates co-localization. Blue, DNA dyed DAPI 


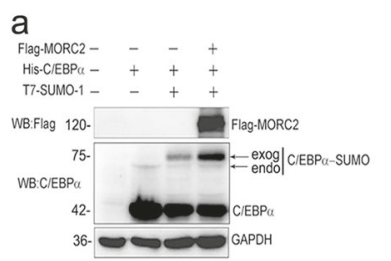

b

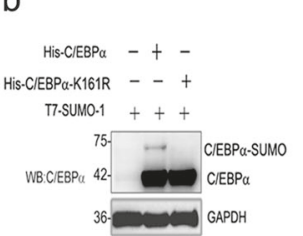

e

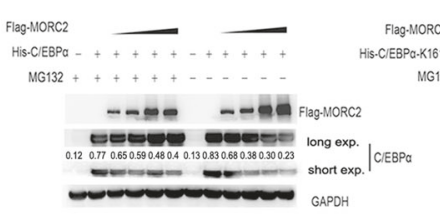

g

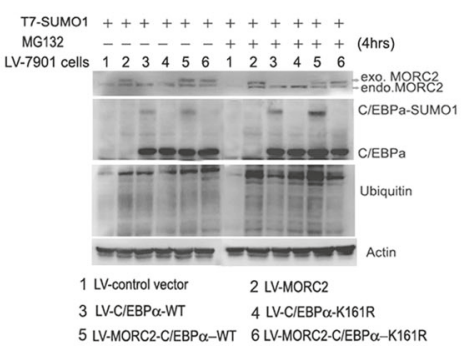

j

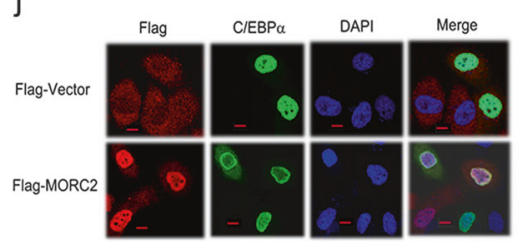

Fig. 3 MORC2 overexpression promotes the sumoylation of C/EBP $\alpha$ and its subsequent degradation. a The sumoylation level of C/EBP $\alpha$ was increased by the ecotopic MORC2. HEK-293TT cells were cotransfected with His-C/EBP $\alpha$, Flag-MORC2, and T7-SUMO1. Total lysates were subjected to western blot with indicated antibodies. $\mathbf{b}$ The deficient sumoylation mutant vector of His-C/EBP $\alpha-\mathrm{K} 161 \mathrm{R}$ was identified. HEK-293T cells were co-transfected with T7-SUMO1 and wild type of His-C/EBP $\alpha$ or SUMO deficient mutant of His-C/EBP $\alpha$ K161R. Total lysates were subjected to western blot with indicated antibodies. c The overexpressed MORC2 increased the sumoylation level of C/EBP $\alpha$, while didn't affect the mutant C/EBP $\alpha-K 161 \mathrm{R}$ level. HEK-293T cells were transfected with the expression vectors for FlagMORC2, T7-SUMO1 and His-C/EBP $\alpha$ or His-C/EBP $\alpha-K 161 \mathrm{R}$, as indicated. Total lysates were subjected to western blot with indicated antibodies. d A cycloheximide (CHX) chase is carried out to really prove that MORC2 affects the stability of the wild-type and not K161R CEBP/ $\alpha$. We co-transfected wild-type His-C/EBP $\alpha$ or mutant C/EBP $\alpha-K 161 R$ and Flag-MORC2 into HEK-293T cells with the cycloheximide (CHX) treatment. After treatment with cycloheximide (CHX) $(50 \mu \mathrm{g} / \mathrm{ml})$ for 4 and $8 \mathrm{~h}$, cell lysates were subjected to western blot with indicated antibodies. e The increased MORC2 affects wildtype not K161 mutant of C/EBP $\alpha$ stability. HEK-293T cells were transfected with the expression vectors for Flag-MORC2 and His-C/ $\mathrm{EBP} \alpha$ or His-C/EBP $\alpha-\mathrm{K} 161 \mathrm{R}$, as indicated. After incubation with MG132 $(10 \mu \mathrm{M})$ for $4 \mathrm{~h}$, cell lysates were subjected to western blot with indicated antibodies. f MORC2 affects the sumoylated C/EBP $\alpha$ and its stability in HEK-293T cells. HEK-293T cells were transfected T7-SUMO1 and these vectors, as indicated in Fig. 3e, cell lysates were d

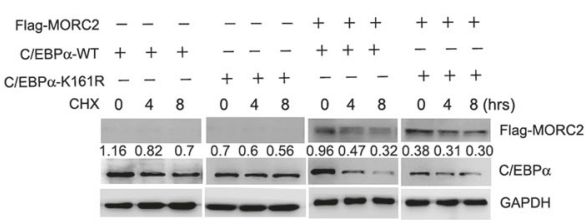

$\mathrm{f}$

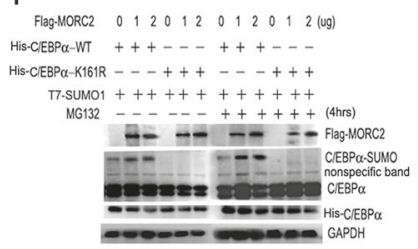

i

Flag-MORC2 ---+-+ His-C/EBP $\alpha$-WT -+++-His-C/EBPQ-K161R +---++ T7-SUMO1 ++++++
MG132 -++++

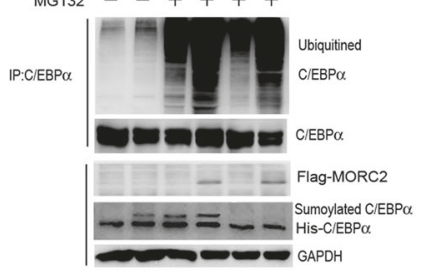

k

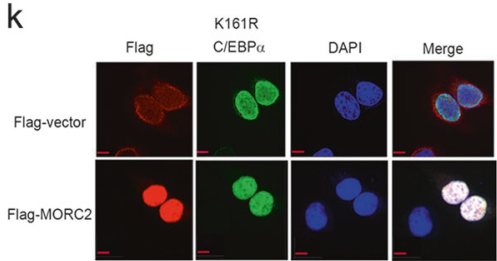

subjected to western blot with indicated antibodies. $\mathrm{g}$ MORC2 promotes the sumoylated $\mathrm{C} / \mathrm{EBP} \alpha$ levels and its stability in stable expressing SGC-7901 cell lines. These lentivirus-mediated cells were transfected with T7-SUMO1 and HA-ub, as indicated. After incubation with MG132 $(10 \mu \mathrm{M})$ for $4 \mathrm{~h}$, cell lysates were subjected to western blot with indicated antibodies. $\mathbf{h}, \mathbf{i}$ IP assays demonstrate that MORC2 promotes the sumoylation of $\mathrm{C} / \mathrm{EBP} \alpha$ and its subsequent degradation in the presence of MG132. HEK-293T cells (h) and stable expressing SGC-7901 cell lines (i) were transfected with T7-SUMO1, as indicated. After incubation with MG132 $(10 \mu \mathrm{M})$ for $4 \mathrm{~h}$, cell lysates were subjected to IP assays with $\mathrm{C} / \mathrm{EBP} \alpha$ antibody, western blot detected with indicated antibodies. $\mathbf{j}$ The nuclear localization of $\mathrm{C} /$ EBP $\alpha$ was observed by confocal microscopy when MORC2 was overexpression. SGC-7901 cells were transiently co-transfected with His-C/EBP $\alpha$ and Flag-MORC2 for $36 \mathrm{~h}$, as indicated, and incubated with Flag-tagged antibody to detect MORC2 expression, specific $\mathrm{C} /$ $\mathrm{EBP} \alpha$ antibody to detect His-C/EBP $\alpha$ expression. Alexa Fluor 488 (green) and Alexa Fluor 546 (red) were used to detect His-C/EBP $\alpha$ and Flag-MORC2 (red) respectively. Yellow indicates co-localization. Blue, DNA dyed DAPI. h The nuclear localization of C/EBP $\alpha-K 161 \mathrm{R}$ was observed by confocal microscopy when MORC2 was overexpression. SGC-7901 cells were transiently co-transfected with His$\mathrm{C} / \mathrm{EBP} \alpha-\mathrm{K} 161 \mathrm{R}$ and Flag-MORC2 for $36 \mathrm{~h}$, and incubated with Flagtagged antibody to detect MORC2 expression, specific C/EBP $\alpha$ antibody to detect His-C/EBP $\alpha-\mathrm{K} 161 \mathrm{R}$ expression. Alexa Fluor 488 (green) and Alexa Fluor 546 (red) were used to detect His-C/EBP $\alpha$ K161R and Flag-MORC2 (red) respectively. Yellow indicates colocalization. Blue, DNA dyed DAPI 
To clarify the reason why MORC2 down-regulates $\mathrm{C} /$ $\mathrm{EBP} \alpha$ expression and whether sumoylation affects its subsequent degradation by the proteasome. As shown in the second lane of Fig. 3d, compared to without $\mathrm{CHX}$ treatment, the protein levels of wild-type $\mathrm{C} / \mathrm{EBP} \alpha$ were largely decreased, while the protein levels of mutant $\mathrm{C} / \mathrm{EBP} \alpha-$ K161R haven't been significantly affected by CHX treatment. To strengthen this point, we performed these assays with the stable co-expressing SGC-7901 cell lines (LVMORC2-C/EBP $\alpha-W T$ and LV-MORC2-C/EBP $\alpha-K 161 R$ ) and got the same results, indicating that the protein levels of $\mathrm{C} / \mathrm{EBP} \alpha-\mathrm{K} 161 \mathrm{R}$ were more stable than $\mathrm{C} / \mathrm{EBP} \alpha-\mathrm{WT}$ with increasing $\mathrm{CHX}$ treatment time (supplementary Figure 1c). These results proved that MORC2 affects the protein stability of the wild-type but not mutant K161R C/EBP $\alpha$. Meanwhile, the protein level of $\mathrm{C} / \mathrm{EBP} \alpha$ was decreased with increasing amounts of MORC2 in HEK-293 cells without MG132 (a specific inhibitor of the proteasome) incubation, while treatment with MG132 largely increased the protein level of $\mathrm{C} / \mathrm{EBP} \alpha$ (Fig. 3e, left panel). However, the protein levels of mutant $\mathrm{C} / \mathrm{EBP} \alpha-\mathrm{K} 161 \mathrm{R}$ had no significant change with the enhancing ectopic MORC2 expression even with MG132 treatment (Fig. 3e, right panel)). In addition, overexpressing MORC2 increased the sumoylation levels of wild-type $\mathrm{C} / \mathrm{EBP} \alpha$ but not $\mathrm{C} / \mathrm{EBP} \alpha-\mathrm{K} 161 \mathrm{R}$ mutant in the presence of T7-sumo1 (Fig. 3f, second lane, column 2 and 3 compared to column 1). MG132 treatment increased sumoylation levels of wild-type $\mathrm{C} / \mathrm{EBP} \alpha$ (Fig. 3f, second lane, column 8 and 9 compared to column 2 and 3) compared to $\mathrm{C} / \mathrm{EBP} \alpha-\mathrm{K} 161 \mathrm{R}$ in the presence of MG132 and MORC2. The same results with lentiviral vectors of SGC7901 cells were indicated that MORC2 promoted the sumoylation of $\mathrm{C} / \mathrm{EBP} \alpha-\mathrm{WT}$ (Fig. 3g, second lane, column 5 compared to column 3), and higher sumoylation levels of $\mathrm{C} / \mathrm{EBP} \alpha-\mathrm{WT}$ showed it undergoes rapid degradation compared with MG132 treatment (Fig. 3g, second lane, column 11 compared to column 5). IP assays further indicated that the sumoylated $\mathrm{C} / \mathrm{EBP} \alpha$ had an increase of ubiquitined $\mathrm{C} /$ $\mathrm{EBP} \alpha$ expression in the presence of MORC2 and MG132 (Fig. 3h, right column 1 compared to column 2 of first lane and Fig. 3i, left column 4 compared to column 3 of first lane). $\mathrm{C} / \mathrm{EBP} \alpha-\mathrm{K} 161 \mathrm{R}$ had less ubiquitin level than $\mathrm{C} /$ $\mathrm{EBP} \alpha-\mathrm{WT}$ in the presence of MG132 and MORC2 (Fig. 3I, first lane,left column 6 compared to column 4), suggesting that MORC2 promotes the sumoylation of wild-type $\mathrm{C} /$ $\mathrm{EBP} \alpha$ and its subsequent degradation.

In addition, the immunofluorescence assays showed that the nuclear localization of $\mathrm{C} / \mathrm{EBP} \alpha$ was less (Fig. 3j, column 2 of down panel) compared to $\mathrm{C} / \mathrm{EBP} \alpha-\mathrm{K} 161 \mathrm{R}$ (Fig. 3k, column 2 of down panel) when MORC2 was overexpressed. The confocal results are consistent with the above (Fig. 2e, down panel). Therefore, these results further indicate that overexpression of MORC2 induces the decreased nuclear localization of $\mathrm{C} / \mathrm{EBP} \alpha$ and be related to the sumoylation of $\mathrm{C} / \mathrm{EBP} \alpha$.

\section{MORC2 overexpression inhibits C/EBPa-mediated C2C12 cell differentiation}

To study whether the expression of MORC2 was involved in $\mathrm{C} / \mathrm{EBP} \alpha$-mediated cell differentiation, we employed the mouse $\mathrm{C} 2 \mathrm{C} 12$ cell lines [22] as a differentiation model. The sub-confluent C2C12 cells of LV-NC and LV-MORC2 (supplementary Figure $2 \mathrm{a}$ and $2 \mathrm{~b}$ ) were induced with differentiation medium (DM) contained 2\% horse serum instead of $10 \%$ fetal bovine serum (FBS) growth medium (GM) at the same time. As reported earlier, after differentiation induction, the $\mathrm{C} 2 \mathrm{C} 12$ cells of LV-NC began elongation and started to form the multi nucleus myotubes $[22,23]$. On the contrary, the C2C12 cells of LV-MORC2 did not respond to the differentiation stimulus, and continued to proliferate until over-confluence (Fig. 4b). With the differentiation process from $\mathrm{C} 2 \mathrm{C} 12$ myoblast to mature myocytes triggered by DM, muscle-related protein expression changed prior to simulation. The mRNA levels of MyoD (myogenic differentiation antigen), myogenin and myosin showed no significant difference in LV-MORC2 C2C12 cells compared to LV-control C2C12 cells (Fig. 4c, "3 group" and "5 group" compared to "0" group). Meanwhile, the $\mathrm{C} / \mathrm{EBP} \alpha \mathrm{mRNA}$ expressed approximately equivalent levels in LV-MORC2 C2C12 cells (Fig. 4c, lower panel,"3 days" and "5 days" compared to "0 day"). The $\mathrm{C} / \mathrm{EBP} \alpha$ protein and its sumoylation levels are gradually decreased in LV-MORC2-C2C12 cells compared to LV-control C2C12 cells (Fig. 4d, "5 days" and "3 days" compared to "1 day"). These results suggest that overexpression of MORC2 could inhibit C2C12 cell differentiation via sumoylation modification.

The $\mathrm{C} / \mathrm{EBP} \alpha-\mathrm{KO} \mathrm{C} 2 \mathrm{C} 12$ cells were generated to further analyze whether MORC2 inhibits $\mathrm{C} / \mathrm{EBP} \alpha$-mediated C2C12 cell differentiation (Fig. 4e). The lentiviral vectors of $\mathrm{C} / \mathrm{EBP} \alpha-\mathrm{WT}$ or $\mathrm{C} / \mathrm{EBP} \alpha-\mathrm{K} 161 \mathrm{R}$ and $\mathrm{MORC} 2$ were infected into the $\mathrm{C} / \mathrm{EBP} \alpha-\mathrm{KO} \mathrm{C} 2 \mathrm{C} 12$ cells to construct stably expressing cells. In the presence of T7-sumo1, the sumoylation levels of $\mathrm{C} / \mathrm{EBP} \alpha$ had stronger band in the $\mathrm{LV}$ MORC2-C/EBP $\alpha-W T$ C2C12 cells than those in $\mathrm{LV}-\mathrm{C} /$ EBP $\alpha-W T$ C2C12 cells (Fig. 4f, left column 4 compared to column 1), not band was found in either $\mathrm{LV}-\mathrm{C} / \mathrm{EBP} \alpha$ K161R or LV-MORC2-C/EBP $\alpha-K 161 R$ cells (Fig. 4f, left column 2 and column 5), indicating that MORC2 promotes the sumoylation of $\mathrm{C} / \mathrm{EBP} \alpha$ in $\mathrm{C} 2 \mathrm{C} 12$ cells. Meanwhile, in the presence of both $\mathrm{HA}-\mathrm{Ub}$ and T7-sumo1, the decreased sumoylation levels of $\mathrm{C} / \mathrm{EBP} \alpha$ (Fig. $4 \mathrm{~g}$, left column 5 compared to column 4 of second lane) and increased ubiquitin expression (Fig. $4 \mathrm{~g}$, left column 5 compared to column 4 of third lane) were found in LV-MORC2-C/EBP $\alpha$ - 


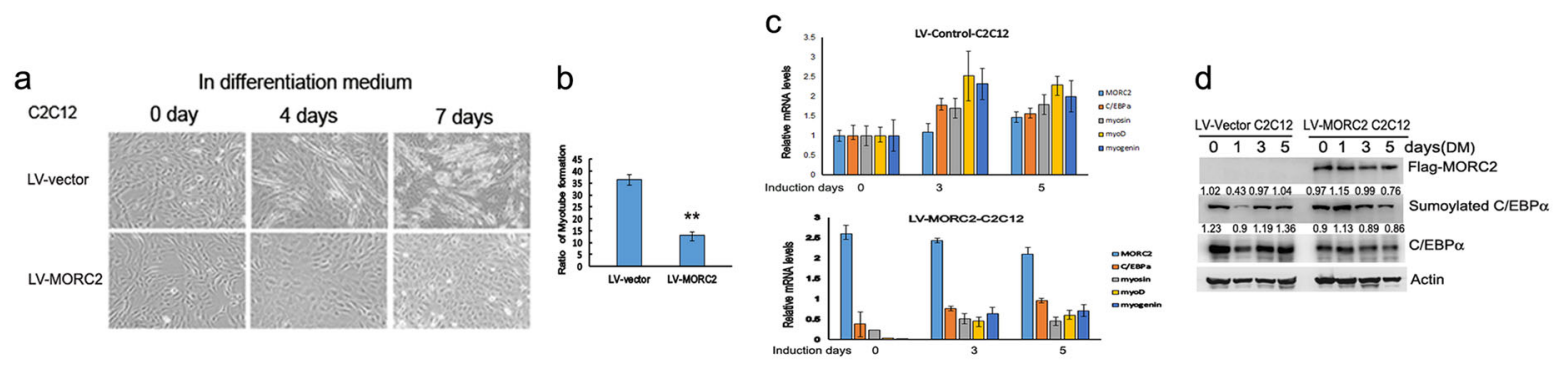

e

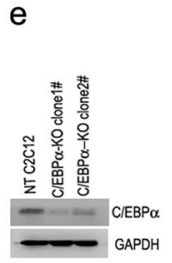

f

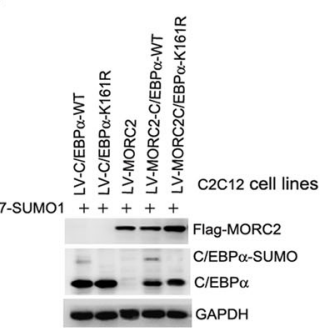

g



h

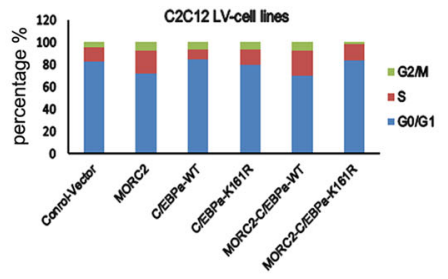

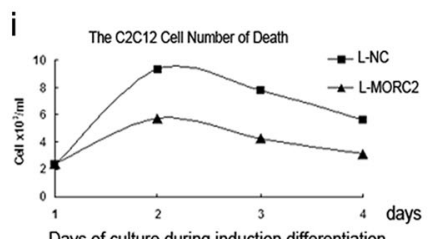

Days of culture during induction differentiation

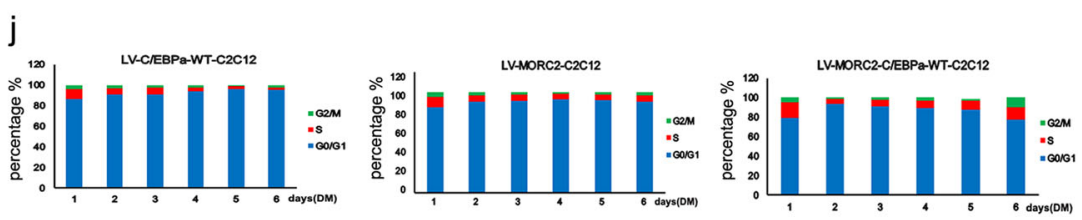

Fig. 4 MORC2 regulates $\mathrm{C} / \mathrm{EBP} \alpha$-mediated $\mathrm{C} 2 \mathrm{C} 12$ muscle cell differentiation. a In differentiation medium MORC2 overexpressing $\mathrm{C} 2 \mathrm{C} 12$ cells keep proliferating and do not start differentiation. Phase-contrast microphoto of $\mathrm{C} 2 \mathrm{C} 12$ and $\mathrm{LV}-\mathrm{MORC} 2$ differentiation cells at 0,4 , and 7 days of differentiation. Original magnification $10 \times$. To induce skeletal muscle differentiation, when reaching 70-80\% confluence, cells of infection with Lentivirus Flag-control vector (LV-NC) and Lentivirus Flag-MORC2 (LV-MORC2) were cultured in DM. DM was changed every 2 days and differentiation was completed in 7 days. b The ratios of myotube formation in LV-MORC2 cells $(13.0 \% \pm 1.5 \%)$ on day 6 of differentiation showed significant less than LV-control vector cells $(36.4 \%$ $\pm 2.2 \%) P<0.0001$. $\mathrm{c}$ With the process from $\mathrm{C} 2 \mathrm{C} 12$ myoblast to mature myocytes triggered by $2 \%$ horse serum, muscle-related protein molecules expression changed prior to simulation. The differentiating $\mathrm{C} 2 \mathrm{C} 12$ myoblast cells was investigated by subjecting confluent $\mathrm{C} 2 \mathrm{C} 12$ cells from GM (growth medium) to DM (differentiation medium) to induce differentiation for 7 days, and isolating mRNA extracts at the indicated time point. Realtime PCR detected the mRNA levels of myoD, myogenin, myosin and C/ EBP $\alpha$. The mRNA levels of MyoD (myogenic differentiation antigen), myogenin and myosin increased gradually in LV-control C2C12 cells (" 3 group" and "5 group" compared to " 0 " group in upper panel) compared to " 0 day" of differentiation (the mRNA levels of LV-control C2C12 in " 0 day" of the differentiation were set to 1 and used as a control), but their expression in LV-MORC2 C2C12 cells showed no significant difference ("3 group" and "5 group" compared to " 0 " group in lower panel) compared to " 0 day" (the mRNA levels of LV-MORC2 C2C12 were the relative ratio to the control vector in " 0 day" of the differentiation, " 0 " group in lower panel). C/EBP $\alpha$ mRNA was decreased in the MORC2 overexpressing $\mathrm{C} 2 \mathrm{C} 12$ compared to control $\mathrm{C} 2 \mathrm{C} 12$ cells in "0 day" (Fig. $4 \mathrm{c}$, lower panel compared to upper panel of " 0 group"), but the C/EBP $\alpha$ mRNA expressed approximately equivalent levels in "3 days" and "5 days" compared to "0 day" (Fig. 4c, lower panel). d The expression levels of $\mathrm{C} / \mathrm{EBP} \alpha$ and MORC were detected with LV-MORC2 and control vector $\mathrm{C} 2 \mathrm{C} 12$ cells during induction differentiation by western blotting. The differentiating $\mathrm{C} 2 \mathrm{C} 12$ myoblast cells was investigated by subjecting confluent $\mathrm{C} 2 \mathrm{C} 12$ cells to induce differentiation for 6 days, and isolating protein extracts at the indicated time point. " 0 day" shown cells

were cultured with growth medium. Total lysate from $\mathrm{C} 2 \mathrm{C} 12$ cells undergoing differentiation was prepared on the days indicated and analyzed by immunoblotting with anti-MORC2, anti-C/EBP $\alpha$ and antiGAPDH. The C/EBP $\alpha$ protein and its sumoylation levels are gradually increased in LV-control vector $\mathrm{C} 2 \mathrm{C} 12$ cells (left panel, "5 days" and "3 days" compared to " 1 day"), its protein and sumoylation levels were gradually decreased in LV-MORC2-C2C12 cells (right panel, "5 days" and " 3 days" compared to " 1 day"). e The C/EBP $\alpha-K O$ C2C12 cells were identified the knockout endogenous $\mathrm{C} / \mathrm{EBP} \alpha$ expression by western blot. $\mathrm{C} 2 \mathrm{C} 12$ cells were transfected with the human C/EBP $\alpha$ double nickase plasmid (from Santa Cruz Company) and Selected with puromycin (2 g/ $\mathrm{mL}$ ) to product stable expressing $\mathrm{C} / \mathrm{EBP} \alpha-\mathrm{KO} \mathrm{C} 2 \mathrm{C} 12$ cells. f MORC2 overexpression promotes the sumoylation of wild-type $\mathrm{C} / \mathrm{EBP} \alpha$ not mutant $\mathrm{K} 161 \mathrm{R}$ in stable co-expressing $\mathrm{C} 2 \mathrm{C} 12$ cells. These stable expressing of $\mathrm{C} 2 \mathrm{C} 12$ cell lines including LV-control vector, LV-MORC2, LV-C/EBP $\alpha$ WT, LV-C/EBP $\alpha-K 161 R$, LV-MORC2-C/EBP $\alpha-W T$ and LV-MORC2$\mathrm{C} / \mathrm{EBP} \alpha-\mathrm{K} 161 \mathrm{R}$ were transfected into T7-sumo1, western blot detected the sumoylation levels of C/EBP $\alpha$ with C/EBP $\alpha$ antibody. g MORC2 promotes the sumoylation of $\mathrm{C} / \mathrm{EBP} \alpha$ and its subsequent degradation. These stable expressing of $\mathrm{C} 2 \mathrm{C} 12$ cell lines as showed in Fig. $4 \mathrm{~g}$ were transfected into T7-sumo1 and HA-ub, western blot detected the sumoylation level of $\mathrm{C} / \mathrm{EBP} \alpha$ and its degradation. h MORC2 promotes C/EBP $\alpha-$ mediated $\mathrm{C} 2 \mathrm{C} 12$ cell cycle transition from G1 to S. Flow cytometry analyzed the cell cycle transition with these stable expressing of $\mathrm{C} 2 \mathrm{C} 12$ cell lines including LV-control vector, LV-MORC2, LV-C/EBP $\alpha-W T$ LV-C/EBP $\alpha-K 161 R$, LV-MORC2-C/EBP $\alpha-W T$ and LV-MORC2-C/ EBP $\alpha-K 161 R$. i The died cell number of LV-NC and LV-MORC2 cells, cell viability was determined by Trypan blue dye exclusion assay. After differentiation induction, we counted dead cell number-collecting cell medium after 1 up to 4 days of differentiation-and expressed it as a percentage of dead cells, floating in medium, on total cells (sum of dead and viable cells, in suspension and adhering to plate). $\mathbf{j}$ MORC2 inhibits $\mathrm{C} / \mathrm{EBP} \alpha-$ mediated $\mathrm{C} 2 \mathrm{C} 12$ cell differentiation via maintaining cell cycle progression. Flow cytometry analyzed cell cycle of LV-C/EBP $\alpha-W T, L V-$ MORC2 and LV-MORC2-C/EBP $\alpha-W T$ cells with the increasing differentiation induction days 
WT cells compared to alone T7-sumo1, indicating that MORC2 can promote sumoylation of $\mathrm{C} / \mathrm{EBP} \alpha$ and its subsequent degradation in $\mathrm{C} 2 \mathrm{C} 12$ cells.

And then, MORC2-C/EBP $\alpha-W T$ cells showed significant increase in the percentage of $\mathrm{S}$ compared to $\mathrm{C} /$ EBP $\alpha-W T$ and MORC2-C/EBP $\alpha-K 161 R$ (Fig. 4h, column 5 compared to column 3 and column 6), indicating that MORC2 promotes $\mathrm{C} / \mathrm{EBP} \alpha$-mediated $\mathrm{C} 2 \mathrm{C} 12$ cell cycle transition from $\mathrm{G} 1$ to $\mathrm{S}$. Furthermore, to analyze the relation between MORC2 overexpression and the axis of differentiation/proliferation, the induction differentiation cells were measured by collecting the dead cells in the DM, the cell death rate indicated that there were not appreciably affected in LV-MORC2 cells compared to LV-control cells with the increasing differentiation induction days (Fig. 4i), suggesting that MORC2 might inhibit $\mathrm{C} 2 \mathrm{C} 12$ cell differentiation. Cell cycle analysis indicated that, with the differentiation process, LV-C/EBP $\alpha-W T$ significantly increased in the percentage of G1 phase cells, and significantly decreased in the percentage of $\mathrm{S}$ phase cells (Fig. $4 \mathrm{j}$, left panel). There was no significant decrease in the percentage of $S$ phase cells in LV-MORC2 cells (Fig. $4 \mathrm{j}$, middle panel) compared to LV-C/EBP $\alpha$-WT cells (Fig. $4 \mathrm{j}$, left panel). However, the co-expression of LV-MORC2-C/ EBP $\alpha$-WT C2C12 cells showed a significant increase in the percentage of $\mathrm{S}$ phase cells (Fig. $4 \mathrm{j}$, right panel) compared to LV-C/EBP $\alpha$-WT cells (Fig. 4j, right panel compared to left panel). In summary, these results indicate that overexpression of MORC2 inhibits C/EBP $\alpha$-mediated $\mathrm{C} 2 \mathrm{C} 12$ cell differentiation and maintains cell proliferation.

In addition, the expression of $\mathrm{C} / \mathrm{EBP} \alpha$ was upregulated in LV-shRNA-MORC2 $\mathrm{C} 2 \mathrm{C} 12$ cells (supplementary Figure 2c). The phase-contrast microscopy observed that the differentiation status of the LV-shRNA-MORC2 C2C12 cells was no significant change compared to LV-shRNAcontrol $\mathrm{C} 2 \mathrm{C} 12$ cells, which might be due to less expression of MORC2 in $\mathrm{C} 2 \mathrm{C} 12$ cells.

\section{MORC2 overexpression attenuates $\mathrm{C} / \mathrm{EBPa}-$ medicated inhibition of cell proliferation}

Emerging evidence shows the critical role of C/EBP $\alpha$ in the regulation of cell growth and cell differentiation [3, 10, 14]. The low level of $\mathrm{C} / \mathrm{EBP} \alpha$ has been observed in various human cancers $[13,14,15]$, suggesting that loss of C/EBP $\alpha$ might be associated to the switch from a cell differentiation to a cell proliferation program in cancer [15]. We, therefore, explored whether MORC 2 expression affected on C/EBP $\alpha$ mediated cell arrest in human cancer. As expected, C/EBP $\alpha$ suppressed cancer cell growth to a greater extent than vector control, while C/EBP $\alpha$ along with Flag-MORC2 attenuated $\mathrm{C} / \mathrm{EBP} \alpha$-mediated cancer cell arrest in SGC-7901 cell lines compared to $\mathrm{C} / \mathrm{EBP} \alpha-\mathrm{K} 161 \mathrm{R}$ plus MORC2 (Fig. 5a). We also got a similar result in MCF-7 cell lines (which has almost no endogenous C/EBP $\alpha$ expression) (Fig. 5b), suggesting that the effect of MORC2 on the proliferation and tumorigenesis of cancer cells is independent of $\mathrm{C} / \mathrm{EBP} \alpha$ expression. In addition, there have significant been evidence to show that the co-expression of MORC 2 and C/EBP $\alpha$-WT formed more colonies (Fig. 5c, left column 4 compared to column 3 and column 6) in vitro and had a significant increase in the percentage of $S$ phase cells (Fig. 5d, left column 5 compared to column 3 and column 6) relative to that seen with $\mathrm{C} / \mathrm{EBP} \alpha-\mathrm{WT}$ and MORC2-C/EBP $\alpha-\mathrm{K} 161 \mathrm{R}$, suggesting that over-expression of MORC2 promotes the growth and cell cycle progression of SGC-7901 via C/EBP $\alpha$ sumoylation.

Subsequently, to further examine the effect of MORC2 and $\mathrm{C} / \mathrm{EBP} \alpha$ on tumorigenesis in vivo. SGC-7901 cells and MCF-7 cells stably expressing Flag-MORC2 were injected into nude mice via right scapular region. Four weeks after injection, the xenografts tumor was obtained for microscopic histological analysis. The results indicated that the overexpressed MORC2 group developed markedly heavier tumor weight (supplementary Figure 3a), larger volume (supplementary Figure 3b) and accelerated PCNA staining (supplementary Figure 3c, right panel) than vector control group, which is consistent with the result of SGC-7901 cell lines [20], indicating that the increased MORC2 expression and low level of $\mathrm{C} / \mathrm{EBP} \alpha$ contribute to proliferation and tumorigenesis of cancer cells. After then, we performed the same assays with SGC-7901 cells of co-expression of LVMORC2-C/EBP $\alpha-W T$ and MORC2-C/EBP $\alpha-K 161 R$ to explore the effect of MORC2 on C/EBP $\alpha$-mediated tumorigenesis in vivo. As shown in Fig. 5, the MORC2-C/ EBP $\alpha-W T$ group get markedly heavier in tumor weight (Fig. 5e) and larger volume (Fig. 5f), and showed stronger PCNA staining (Fig. 5g, down panel) than MORC2-C/ EBP $\alpha-K 161 R$ group. The formation of xenografts tumor with anti-MORC2 (Fig. 5g, upper panel) and anti-C/EBP $\alpha$ (Fig. 5g, middle panel) staining in nude mice tissues were verified by immunohistochemical analysis. Taken together, these findings suggest that MORC2 overexpression attenuate $\mathrm{C} / \mathrm{EBP} \alpha$-medicated inhibition of cell proliferation and tumorigenesis in gastric cancer via sumoylation.

\section{The increased MORC2 expression negatively correlates with C/EBPa expression and the poor differentiation status of gastric cancer}

Following, we determined the expression of MORC2 and $\mathrm{C} / \mathrm{EBP} \alpha$ in gastric cancer tissues and matched adjacent normal tissues from 40 cases gastric tumor patients by performing immunochemical staining of MORC2 and $\mathrm{C} /$ EBP $\alpha$. The increased nuclear staining of MORC2 was observed in poor differentiation gastric cancer compared to 

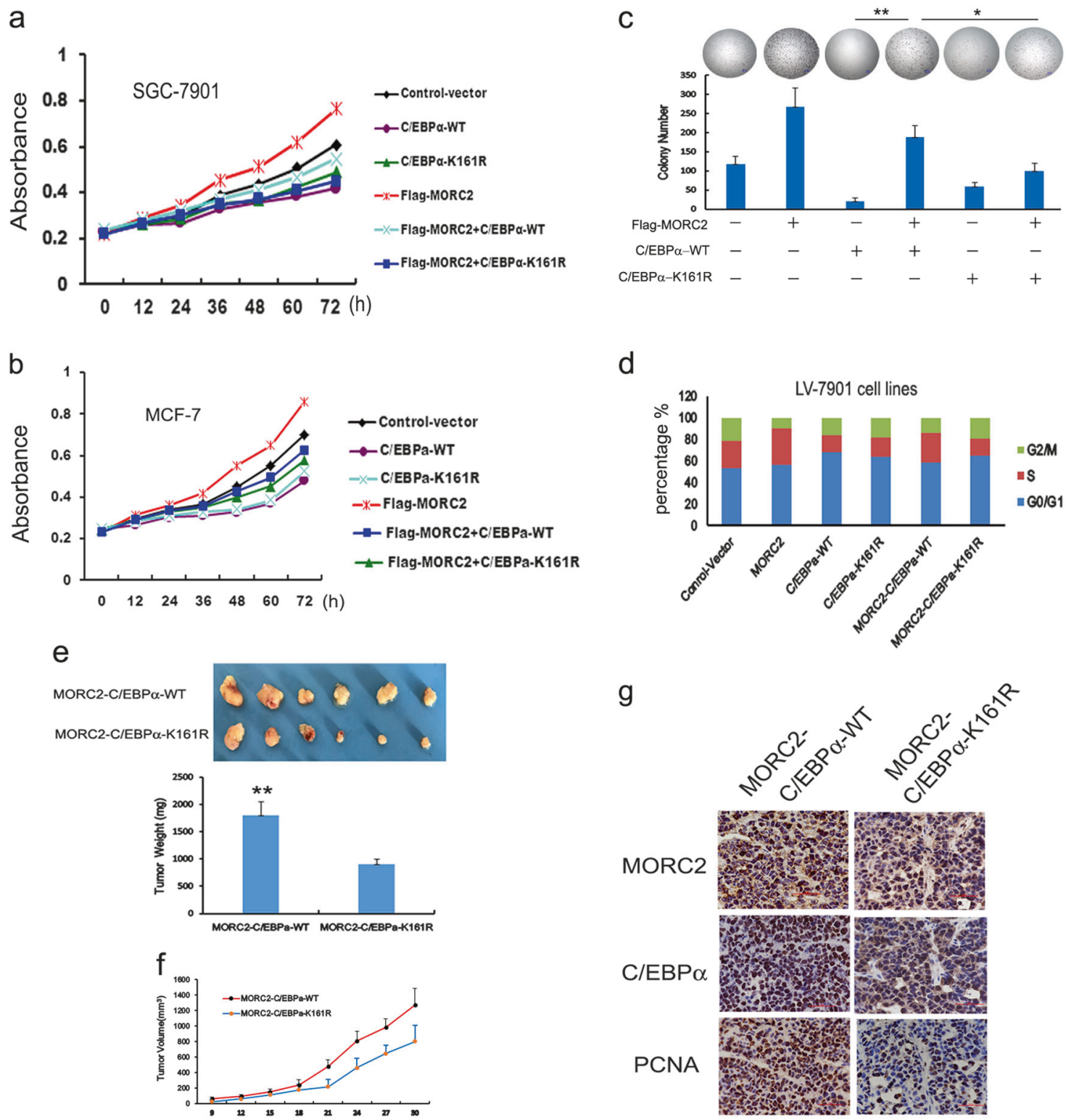

Fig. 5 Overexpression of $\mathrm{MORC} 2$ attenuates $\mathrm{C} / \mathrm{EBP} \alpha-$ medicated inhibition of cell proliferation. a, b The stable expressing FlagMORC2 of SGC-7901 cells and MCF-7 cells were transiently transfected with His-C/EBP $\alpha$, and analyzed for cell growth for every $12 \mathrm{hrs}$ by cell counts assay. Values are the means \pm SD from three individual experiments. c The stable expressing Flag-MORC2 of SGC-7901 cells were transfected with wild type and K161R of His-C/EBP $\alpha$ and performed by colony formation assays. Representative results are shown. d Cell cycle analysis indicate that MORC2-C/EBP $\alpha-W T$ not MORC2$\mathrm{C} / \mathrm{EBP} \alpha-\mathrm{K} 161 \mathrm{R}$ promotes cells transition from $\mathrm{G} 1$ to $\mathrm{S}$ compared to

well-moderate differentiation and adjacent normal tissues (Fig. 6a, upper panel), poor differentiation gastric cancer tissues with high levels of MORC2 accounted for $~ 80 \%$ of gastric cancer samples (Fig. 6a, upper panel), which showed the striking correlation with decreased C/EBP $\alpha$ (Fig. 6a, down panel). Conversely, the increased $\mathrm{C} / \mathrm{EBP} \alpha$ expression was shown in adjacent normal tissues and well-moderate
$\mathrm{C} / \mathrm{EBP} \alpha-\mathrm{WT}$ cells and control vector cells. e, g MORC2-C/EBP $\alpha$-WT and MORC2-C/EBP $\alpha-K 161 \mathrm{R}$ cells were injected into right scapular region of the nude mice ( $n=6$ per group). The inoculated mice were terminated in 3 weeks. Each tumor lump was removed from the body. e Photographs of tumor weight were quantified. $\mathbf{f}$ Tumor volumes were measured and data are mean \pm SEM. $\mathbf{g}$ Immunohistochemistry staining of anti-MORC2 and anti-C/EBPa were indicated in nude mice tumor tissues sections, Original magnification, $\times 400$. Degree of intratumoral proliferation was determined by PCNA staining

differentiation gastric cancer tissues, along with the decreased MORC2 expression (Fig. 6a, down panel). The down-regulation of $\mathrm{C} / \mathrm{EBP} \alpha$ and up-regulation of MORC2 accounted for $\sim 80 \%$ in 40 cases of gastric tumor patients (Fig. 6b). TCGA public data indicated that low C/EBP $\alpha$ expression accounted for $60 \%$ in MORC2 high expression group (Fig. 6c). Taken together, the reciprocal expression of 


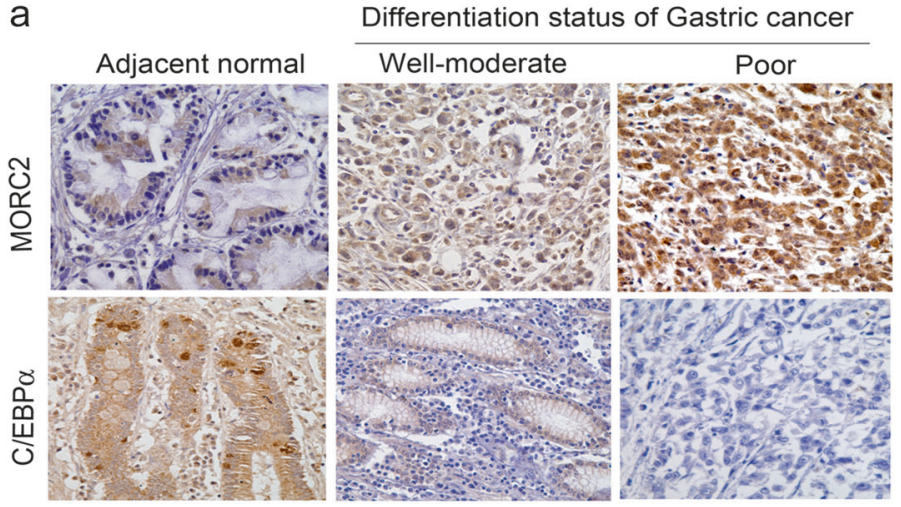

b
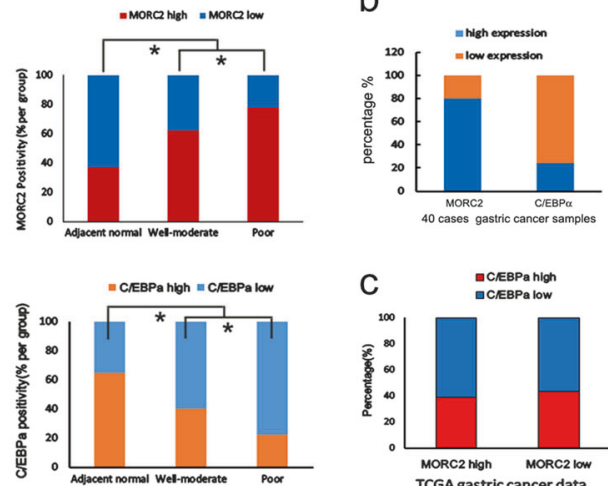

d

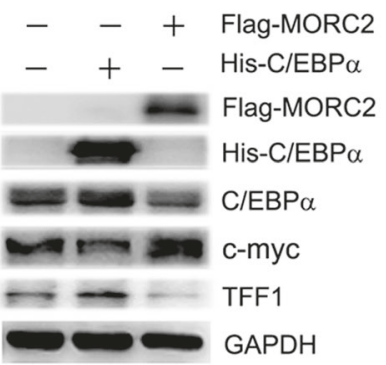

g

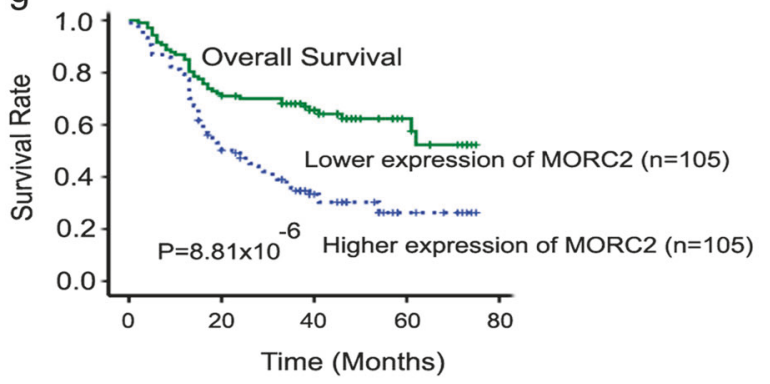

Fig. 6 The expression of MORC2 negatively correlates with the differentiation status of gastric cancer. a Immunohistochemical analysis of MORC2 and C/EBP $\alpha$ expression in normal gastric tissues, wellmoderate differentiation gastric cancer and differentiation poor gastric cancer tissues. Scale bar, $50 \mu \mathrm{m}$. Representative IHC images were shown. The levels of MORC2 and C/EBP $\alpha$ were analyzed in the different differentiation status of gastric cancer samples. b The levels of $\mathrm{C} / \mathrm{EBP} \alpha$ and MORC2 were analyzed with 40 cases of gastric tumor patients. The down-regulation of $\mathrm{C} / \mathrm{EBP} \alpha$ and up-regulation of MORC2 accounted for $\sim 80 \%$ in 40 cases of gastric tumor patients. c Low $\mathrm{C} / \mathrm{EBP} \alpha$ expression accounted for $60 \%$ in high expression of MORC2 group. By analyzing the downloaded TCGA gastric cancer public data with expression values of MORC2 and $\mathrm{C} / \mathrm{EBP} \alpha$, the expression level in normal tissues and tumor tissues was measured with respective media. Expression value higher than the media is identified as high expression. Vice versa, that is low expression. d Western blot detected the protein levels of c-myc and TFF1 when

low $\mathrm{C} / \mathrm{EBP} \alpha$ and high MORC2 is associated with maintaining the different differentiation status of gastric cancer.

TFF1, an identified gastric differentiation marker [24], showed to be accompanied by the expression level of $\mathrm{C} /$ $\mathrm{EBP} \alpha[15]$. C/EBP $\alpha$ can inhibit c-myc expression, f

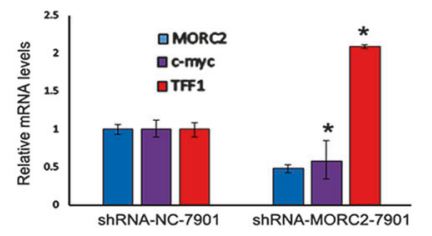

h

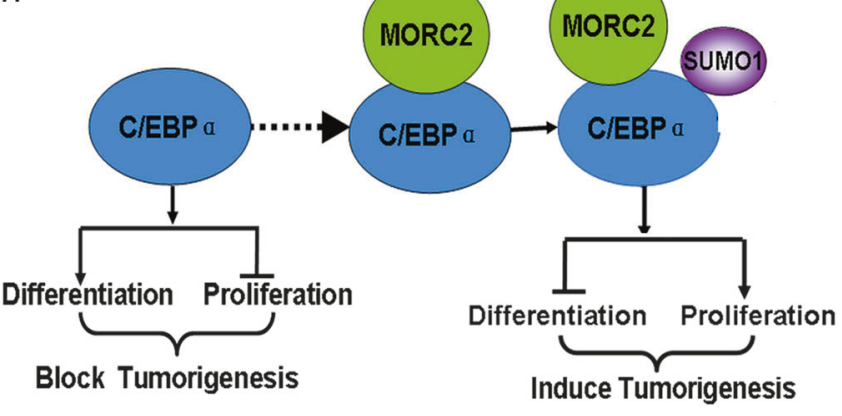

(a)

(b)

MORC2 or C/EBP $\alpha$ was overexpression in SGC-7901 gastric cancer cells. e QPCR detected the mRNA levels of c-myc and TFF1 when MORC2 was overexpression in SGC-7901 gastric cancer cells. f QPCR detected the mRNA levels of c-myc and TFF1 when MORC2 was knockdown in SGC-7901 gastric cancer cells. g KaplanMeier's analyses illustrated that the 5-year survival rate according to MORC2 protein expression on 210 gastric cancer patients. The lowerexpression group was defined as those at or below the median value (1.2-fold), whereas the higher-expression group consisted of patients expressing levels above (1.2-fold). $\mathbf{h}$ Model of the role of MORC2 in $\mathrm{C} / \mathrm{EBP} \alpha-$ mediated differentiation and tumorigenesis. In the absent of MORC2, $\mathrm{C} / \mathrm{EBP} \alpha$ plays a role in cell differentiation promotion and inhibition of cell proliferation, which may block tumorigenesis. While in the present of MORC2 overexpression, MORC2 interacts with $\mathrm{C} /$ $\mathrm{EBP} \alpha$ and promotes the sumoylation of $\mathrm{C} / \mathrm{EBP} \alpha$ and its subsequent degradation, which will lead to tumorigenesis

promoting cellular differentiation and growth arrest [25]. Therefore, we further confirmed this point in SGC-7901 gastric cancer cells and obtained the same conclusions, which indicated that the low protein levels of c-myc (Fig. 6d, column 2 of lane 4) and high protein levels of 
TFF1 (Fig. 6d, column 2 of lane 5) when C/EBP $\alpha$ was overexpression. Meanwhile, we also found that the expression of c-myc was high (Fig. 6d, column 3 of lane 4 and Fig. 6e, column 5) and TFF1 was low (Fig. 6d, column 3 of lane 5 and Fig. 6e, column 6) in the presence of MORC2 overexpression. Conversely, low mRNA level of c-myc (Fig. 6f, column 5) and high level of TFF1 (Fig. 6f, column 6) were shown when MORC2 was knocked out. In summary, these results indicated that MORC2 inhibited C/ EBP $\alpha$-mediated signal, which leads to the switch from a cell differentiation to a cell proliferation program in cancer.

In addition, we studied the correlation between MORC2 expression and clinicopathological characteristics in 210 gastric cancer samples. The results (Table $1, \mathrm{P}$ bold values of $P<0.05$ indicate statistical significance) showed that high expression of MORC2 was significantly associated with tumor size $(P=0.020)$, poor differentiation $(P=0.042)$, poor depth of invasion $(\mathrm{pT})$ stage $(P=0.002)$, poor distant metastasis $(\mathrm{pM})$ stage $(P=0.005)$ and poor pathological stage (pTNM stage) stage $(P=0.021)$. Moreover, overexpression of MORC2 in clinical gastric cancer was also found to predict shorter overall survival of patients $\left(P=8.81 \times 10^{-8}\right.$; Fig. $\left.6 \mathrm{~g}\right)$. These findings suggest MORC2 as a potential prognostic marker and therapeutic target for gastric cancer.

\section{Discussion}

Microrchidia (MORC) is a highly conserved nuclear protein family. MORC2 as a member of MORC family, ubiquitously expressed in human cells and tissues, which has been found to be involved in several nuclear functions including repression gene transcription and regulation chromatin remodeling during the DNA-damage response [16]. In addition, MORC2 was shown to exert its cytosolic function in lipogenesis and adipogenic differentiation [19]. Our recent research found an association between MORC2 and gastric cancer [20, 21]. In this study, we demonstrate that MORC2 interacts with $\mathrm{C} / \mathrm{EBP} \alpha$ and promotes the sumoylation of $\mathrm{C} / \mathrm{EBP} \alpha$ and its subsequent degradation, which explores a different mechanism from previous studies to MORC2 function.

Previous studies have implied that muscle cell formation occurs at low $\mathrm{C} / \mathrm{EBP} \alpha$ levels while adipocyte-specific differentiation requires maximum $\mathrm{C} / \mathrm{EBP} \alpha$ expression [33]. The multipotent $\mathrm{C} 2 \mathrm{C} 12$ mesenchymal progenitor cells can differentiate into adipocyte, muscle cells and osteoblasts. The decision of adipocyte or muscle cell differentiation is involved the expression level of C/EBP $\alpha[26,27]$. Here, we examined the role of MORC2 in cell differentiation using the $\mathrm{C} 2 \mathrm{C} 12$ cells. Upon treatment with containing $2 \%$ horse serum DM, compared to differentiated control cells (LV$\mathrm{NC}-\mathrm{C} 2 \mathrm{C} 12)$, the ectopic expression of MORC2 in $\mathrm{C} 2 \mathrm{C} 12$
Table 1 Comparison of expression levels of MORC2 with clinicopathological features in 210 patients with gastric cancer tissues

\begin{tabular}{|c|c|c|c|}
\hline & No. & MORC2 fold ${ }^{\mathrm{a}}$ & $P$-value* \\
\hline \multicolumn{4}{|l|}{ Age (years) } \\
\hline$\geq 65$ & 82 & $2.60(2.00-2.85)$ & \multirow[t]{2}{*}{0.389} \\
\hline$<65$ & 128 & $2.45(2.00-2.75)$ & \\
\hline \multicolumn{4}{|l|}{ Sex } \\
\hline Male & 158 & $2.55(2.00-2.80)$ & \multirow[t]{2}{*}{0.103} \\
\hline Female & 52 & $2.35(1.85-2.75)$ & \\
\hline \multicolumn{4}{|l|}{ Tumor size $(\mathrm{cm})$} \\
\hline$\geq 4$ & 136 & $2.65(2.10-2.80)$ & \multirow[t]{2}{*}{0.020} \\
\hline$<4$ & 74 & $2.35(1.85-2.75)$ & \\
\hline \multicolumn{4}{|l|}{ Histological grade } \\
\hline Low & 59 & $2.35(1.85-2.75)$ & \multirow[t]{2}{*}{0.042} \\
\hline High & 151 & $2.55(2.00-2.80)$ & \\
\hline \multicolumn{4}{|l|}{ Macroscopic type } \\
\hline Early stage & 30 & $2.25(2.00-2.70)$ & \multirow[t]{3}{*}{0.382} \\
\hline Borrmann I + II & 16 & $2.70(2.00-2.825)$ & \\
\hline IV & 164 & $2.55(2.00-2.80)$ & \\
\hline \multicolumn{4}{|c|}{ Depth of invasion (pT) } \\
\hline $\mathrm{T} 1+\mathrm{T} 2$ & 171 & $2.45(1.90-2.75)$ & \multirow[t]{2}{*}{0.002} \\
\hline $\mathrm{T} 3+\mathrm{T} 4$ & 39 & $2.70(2.55-2.85)$ & \\
\hline \multicolumn{4}{|c|}{ Lymph node status (pN) } \\
\hline $\mathrm{N} 0+\mathrm{N} 1$ & 148 & $2.375(1.90-2.80)$ & \multirow[t]{2}{*}{0.09} \\
\hline $\mathrm{N} 2+\mathrm{N} 3$ & 62 & $2.65(2.20-2.80)$ & \\
\hline \multicolumn{4}{|c|}{ Distant metastasis (pM) } \\
\hline No & 197 & $2.45(2.00-2.75)$ & \multirow[t]{2}{*}{0.005} \\
\hline Yes & 13 & $2.85(2.65-2.85)$ & \\
\hline \multicolumn{4}{|c|}{ Pathological stage (pTNM stage) } \\
\hline Stage I + II & 112 & $2.35(1.95-2.75)$ & \multirow[t]{2}{*}{0.021} \\
\hline Stage III + IV & 98 & $2.65(2.10-2.80)$ & \\
\hline
\end{tabular}

*Indicated statistical significance $(P<0.05)$

${ }^{\text {a } M e d i a n ~ o f ~ r e l a t i v e ~ e x p r e s s i o n, ~ w i t h ~} 25$ th-75th percentile in parenthesis

cells impaired muscle cells differentiation, and indicated that dramatically down-regulated the expression level of C/ EBP $\alpha$. Interestingly, recent study indicated that the knockdown of MORC2 in 3T3-L1cells inhibited adipocyte differentiation upon stimulation with the adipocyte differentiation, and showed the decreased expression level of C/EBP $\alpha$ [19], suggesting that MORC2 up-regulate C/ $\mathrm{EBP} \alpha$ expression and promote adipogenic differentiation in 3T3-L1cells by promoting ACLY activity. These data indicate that, in different cell types and different stimulation, MORC2 may either down-regulate C/EBP $\alpha$ expression to impair muscle differentiation, or can up-regulate $\mathrm{C} / \mathrm{EBP} \alpha$ expression to promote adipocyte differentiation, suggesting that MORC2 may modulate the $\mathrm{C} / \mathrm{EBP} \alpha$-mediated differentiation control switch to decide cell fate. The dualregulated expression of $\mathrm{C} / \mathrm{EBP} \alpha$ by $\mathrm{MORC} 2$ enables 
precise insight into combinatorial effects of two key differentiation factors involved in differentiation control switch. Although, in our study, we used the mouse $\mathrm{C} 2 \mathrm{C} 12$ cell line and cancer cell lines to study MORC2 involved in cell differentiation and proliferation, we can draw a conclusion that the over-expression of MORC2 can inhibit cell differentiation and promote cell proliferation.

Thus, based on our novel findings, we propose a model (Fig. 6h) for the role of MORC2 controlling C/EBP $\alpha$ expression via sumoylation to regulate the switch from a cell differentiation (Fig. 6h-a) to a cell proliferation (Fig. 6h-b) program and induce the tumorigenesis. In this study, we found that the overexpression of MORC2 downregulated the C/EBP $\alpha$ expression via sumoylation modification to inhibit differentiation and resulted in gastric tumorigenesis. We can draw a conclusion that MORC2 inhibits $\mathrm{C} / \mathrm{EBP} \alpha$-mediated signal pathway which involves in the switch from a cell differentiation to a cell proliferation program in cancer.

Recent studies show morc 2 mutations are absent in some diseases and cancer patients [28-32], implicating the emerging importance of MORC2 in human disease and cancers. Importantly, our results indicated that overexpression of MORC2 associated with poor differentiation status of gastric cancer, tumor size, depth of invasion, distant metastasis, pathological stage and 5-year survival rate in clinical gastric cancer, suggesting that MORC2 may be involved in progression and prognosis of gastric cancer. Meanwhile, the result also suggest that MORC2 may have a relation to metastasis in clinical gastric cancer which will be studied in our future. Therefore, evidence is mounting in implicating MORC2 as an oncogene. Further study of MORC2 may provide promising new therapeutic targets for gastric cancer.

\section{Methods}

\section{Cell cultures, differentiation assays, and lentiviral productions}

HEK-293T cells, gastric cancer SGC-7901 and BGC-823 cells and breast cancer MCF-7 cells, mouse $\mathrm{C} 2 \mathrm{C} 12$ cells were maintained in Dulbecco's modified Eagle's medium (DMEM, GIBCO) supplemented with 10\% FBS, $100 \mathrm{U} / \mathrm{ml}$ penicillin and $100 \mu \mathrm{g} / \mathrm{ml}$ streptomycin at $37^{\circ} \mathrm{C}$ in $5 \% \mathrm{CO}_{2}$. $\mathrm{C} 2 \mathrm{C} 12$ cells was induce differentiation from GM to DM for 7 days, the procedures were performed according to the previously described [22]. Recombinant MORC2-lentivirus including shRNA-MORC2, overexpression of LV-MORC2, LV- C/EBP $\alpha-W T$, LV-C/EBP $\alpha-K 161 R$, and LV-control vectors were purchased from Shanghai GeneChem Company. According to the manufacturer's protocol, cells were infected with lentivirus in 12-well dishes in the presence of polybrene $(4 \mathrm{~g} / \mathrm{mL})$. Selection with puromycin $(2 \mathrm{~g} / \mathrm{mL})$ was started $48 \mathrm{~h}$ after lentiviral transduction to product stable expression MORC2. Infected cells were identified by Western blot.

\section{Plasmid construction, mutagenesis, and cell transfection}

His-pcDNA3.1-C/EBP $\alpha$ and pGEX-2T-C/EBP $\alpha$ plasmids were generously provided by Drs. Friedman AD [33] and Dr. Smola-Hess S [34]. T7-SUMO1 expression plasmid was kindly gifted by $\mathrm{Hu}$ [35]. C/EBPa Double Nickase plasmid (h) was ordered from Santa Cruz company. The human full length and truncated versions of pcDNA-hisMORC2 were generated as described previously [17]. The Flag-MORC2 and GST-MORC2 vectors were acquired by $\mathrm{KpnI}$ and XhoI using the pcDNA3.1-MORC2 as template. The truncations of $\mathrm{C} / \mathrm{EBP} \alpha$ were cloned into the HispcDNA3.1A vector. Mutation on K161R was generated using the Quickchange-XL Site-Directed Mutagenesis kit (Stratagene) from the His-C/EBP $\alpha$ plasmid of full length. The specific PCR primers are shown in Supplementary Table 1. Cells were transfected with siRNA and plasmid vectors using Lipofectamine 2000 (Invitrogen).

\section{Reverse transcription and quantitative real-time PCR}

Total cellular RNA was extracted using TRIzol (Tiangen) according to the manufacturer's protocol. One microgram of total RNA was reverse transcribed to cDNA in a total volume of $20 \mu \mathrm{l}$ system using a RT reaction kit (Tiangen). Quantitative Real-time PCR was performed using a Mx 3000P real-time PCR system (Applied Biosystems) according to the manufacturer's instruction and $\mathrm{SYBR}^{\circ}$ Premix Ex Taq (TaKaRa) as a DNA-specific fluorescent dye. PCR was carried out for 50 cycles of $95^{\circ} \mathrm{C}$ for $10 \mathrm{~s}$ and $60{ }^{\circ} \mathrm{C}$ for $30 \mathrm{~s}$. The specific PCR primers are shown in Supplementary Table 2 . All the reactions were repeated at least three times. Gene expression levels were calculated relative to the housekeeping gene GAPDH by using Stratagene Mx $3000 \mathrm{P}$ software.

\section{GST pull-down assay, Western blot, and immunoprecipitation assay}

In vitro transcription and translation of His-MORC2 or Flag-C/EBP $\alpha$ proteins were performed by using the TNTcoupled transcription and translation system (Promega), as previously described [20]. The procedures of western blot and Immunoprecipitation assays were performed as previously described [17]. Primary antibody dilution and order 
company of His (1:2000, GenScript Corporation), c-myc and sumo1 (1:1000, Santa Cruz) and C/EBP $\alpha$ and Ubiquitin (1:1000, Cell Signaling Technology); Flag (1:2000, Shang Hai, Genomics); MORC2 (1:2000, Abcam);TFF1(1:1000, Protein tech Group).

\section{Confocal imaging}

SGC-7901 cells co-transfected with His-C/EBP $\alpha$ together with Flag-vector or Flag-MORC2 grown on glass coverslips were fixed in methanol at room temperature for $15 \mathrm{~min}$, and blocked with normal goat serum for $1 \mathrm{~h}$. The cells were incubated with mouse anti-Flag-tagged antibody and rabbit anti-C/EBP $\alpha$ antibody for overnight at $4{ }^{\circ} \mathrm{C}$, and washed three times in PBST (PBS with 1\%o TritonX-100).Then incubated with mouse anti-goat Alexa-594 and rabbit anti-goat Alexa488 secondary antibodies (1:100, Molecular Probes) for $1 \mathrm{~h}$ at room temperature, washed three times in PBST. The DNA dye DAPI was used to co-stain the DNA (blue). Confocal scanning analysis was performed by using a Leika laser confocal scanning microscope in accordance with established methods, utilizing sequential laser excitation to minimize the possibility of fluorescent emission bleed-through.

\section{Cell cycle analysis, growth curve, and colony formation assay}

Stable overexpressed cell lines were seeded in $60-\mathrm{mm}$ plates to perform the flow cytometry and cell counts assays as described in our previous paper [17, 20]. For colony formation assay, 500 cells were plated in six-well plates to assess the proliferation potential of cells and incubated at $37^{\circ} \mathrm{C}$ in a $5 \% \mathrm{CO}_{2}$ incubator. After 2 weeks, the number of colonies was counted. Data represent the mean \pm SD from three independent experiments performed in triplicate wells

\section{Mouse models}

The Ethics Committee of China Medical University approved the study protocol for the use of experimental animals. Female Balb/c nude mice (18-22 g) were purchased from Beijing Vital River Laboratory Animal Technology Company (Beijing, China). To assess role of MORC2 in breast tumor progression, each mouse was injected subcutaneously with $2 \times 10^{6}$ cells in $0.2 \mathrm{ml}$ PBS into right scapular region. Four groups $(5$ each) of mice were injected MCF-7 cells with lentivirus-mediated stable expression of MORC2 and control vector including shRNA-MORC2, respectively. Tumor size was measured every 2 days with calipers. The tumor volume was calculated based on the formula $\left(L \times W^{2}\right) / 2$, where $L$ is length and $W$ is width. Mice were sacrificed after 6 weeks, and the xenograft volume was monitored by weight.

\section{Tumor tissue samples and immunohistochemistry}

Samples of human gastric cancer tissues, paired-adjacent non-tumor gastric tissues and paraffin-embedded gastric tumor tissues were obtained from the First Hospital of China Medical University, as previously described [20]. Fresh samples were rapidly frozen in liquid nitrogen immediately after resection and stored at $-80^{\circ} \mathrm{C}$. All samples were obtained with patients' informed consent and were histologically confirmed by staining with hematoxylin-eosin. The histological grade of cancers was assessed according to criteria set by the World Health Organization. All research involving human participants have been approved by the First Hospital of China Medical University ethics committees. The Immunohistochemistry procedures and intensity of images were analyzed as previously described $[20,21]$.

\section{Statistical analysis}

Quantitative data are presented as mean values \pm SEM (standard error of the mean) from $\geq 3$ independent repetitions. Statistical comparisons between groups were carried out with the use of 2-tailed Student $t$ test. A $p$-value of $p<$ 0.05 was considered as statistically significant.

Acknowledgements We thank Dr. Friedman AD (Johns Hopkins University, USA) and Dr. Smola-Hess S (University of Cologne, Germany) generously provided with the pcDNA3.1-C/EBP $\alpha$ and pGEX-2T-C/EBP $\alpha$ plasmids. We also thank Dr. Jing Hu (University of Pittsburgh Cancer Institute, USA) kindly gifted with the T7SUMO1 expression plasmid. This work was financially supported by grants from the National Natural Science Foundation of China (81572611, 81828009, 30871294, and 81502400).

\section{Compliance with ethical standards}

Conflict of interest The authors declare that they have no conflict of interest.

Publisher's note: Springer Nature remains neutral with regard to jurisdictional claims in published maps and institutional affiliations.

Open Access This article is licensed under a Creative Commons Attribution 4.0 International License, which permits use, sharing, adaptation, distribution and reproduction in any medium or format, as long as you give appropriate credit to the original author(s) and the source, provide a link to the Creative Commons license, and indicate if changes were made. The images or other third party material in this article are included in the article's Creative Commons license, unless indicated otherwise in a credit line to the material. If material is not included in the article's Creative Commons license and your intended use is not permitted by statutory regulation or exceeds the permitted use, you will need to obtain permission directly from the copyright holder. To view a copy of this license, visit http://creativecommons. org/licenses/by/4.0/. 


\section{References}

1. Zheng L, Wang L, Ajani J, Xie K. Molecular basis of gastric cancer development and progression. Gastric Cancer. 2004;7: 61-77.

2. Schuster MB, Porse BT. C/EBPalpha: a tumour suppressor in multiple tissues? Biochim Biophys Acta. 2006;1766:88-103.

3. Loomis KD, Zhu S, Yoon K, Johnson PF, Smart RC. Genetic ablation of CCAAT/enhancer binding protein alpha in epidermis reveals its role in suppression of epithelial tumorigenesis. Cancer Res. 2007;67:6768-76.

4. Khanna-Gupta A. Sumoylation and the function of CCAAT enhancer binding protein alpha (C/EBP alpha). Blood Cells Mol Dis. 2008;41:77-81.

5. Wilkinson KA, Henley JM. Mechanisms, regulation and consequences of protein SUMOylation. Biochem J. 2010;428: 133-45.

6. Lin DY, Huang YS, Jeng JC, Kuo HY, Chang CC, Chao TT, et al. Role of SUMO-interacting motif in Daxx SUMO modification, subnuclear localization, and repression of sumoylated transcription factors. Mol Cell. 2006;24:341-54.

7. Subramanian L, Benson MD, Iniguez-Lluhi JA. A synergy control motif within the attenuator domain of CCAAT/enhancer-binding protein alpha inhibits transcriptional synergy through its PIASyenhanced modification by SUMO-1 or SUMO-3. J Biol Chem. 2003;278:9134-41.

8. Kim J, Cantwell CA, Johnson PF, Pfarr CM, Williams SC. Transcriptional activity of CCAAT/enhancer-binding proteins is controlled by a conserved inhibitory domain that is a target for sumoylation. J Biol Chem. 2002;277:38037-44.

9. Ramji DP, Foka P. CCAAT/enhancer-binding proteins: structure, function and regulation. Biochem J. 2002;365(Pt 3):561-75.

10. Sato Y, Miyake K, Kaneoka H, Iijima S. Sumoylation of CCAAT/ enhancer-binding protein alpha and its functional roles in hepatocyte differentiation. J Biol Chem. 2006;281:21629-39.

11. Oh Y, Chung KC. Small ubiquitin-like modifier (SUMO) modification of zinc finger protein 131 potentiates its negative effect on estrogen signaling. J Biol Chem. 2012;287:17517-29.

12. Geletu M, Balkhi MY, Peer Zada AA, Christopeit M, Pulikkan JA, Trivedi AK, et al. Target proteins of C/EBPalphap30 in AML: C/EBPalphap30 enhances sumoylation of C/EBPalphap42 via upregulation of Ubc9. Blood. 2007;110:3301-9.

13. Lourenco AR, Coffer PJ. A tumor suppressor role for C/EBPalpha in solid tumors: more than fat and blood. Oncogene. 2017;36: 5221-30.

14. Pulikkan JA, Tenen DG, Behre G. C/EBPalpha deregulation as a paradigm for leukemogenesis. Leukemia. 2017;31:2279-85.

15. Regalo G, Resende C, Wen X, Gomes B, Duraes C, Seruca R, et al. C/EBP alpha expression is associated with homeostasis of the gastric epithelium and with gastric carcinogenesis. Lab Invest. 2010;90:1132-9.

16. Hong G, Qiu H, Wang C, Jadhav G, Wang H, Tickner J, et al. The emerging role of MORC family proteins in cancer development and bone homeostasis. J Cell Physiol. 2017;232:928-34.

17. Wang GL, Wang CY, Cai XZ, Chen W, Wang XH, Li F. Identification and expression analysis of a novel CW-type zinc finger protein MORC2 in cancer cells. Anat Rec. 2010;293:1002-9.

18. Li DQ, Nair SS, Ohshiro K, Kumar A, Nair VS, Pakala SB, et al. MORC2 signaling integrates phosphorylation-dependent, ATPase-coupled chromatin remodeling during the DNA damage response. Cell Rep. 2012;2:1657-69.
19. Sanchez-Solana B, Li DQ, Kumar R. Cytosolic functions of MORC2 in lipogenesis and adipogenesis. Biochim Biophys Acta. 2014;1843:316-26.

20. Wang G, Song Y, Liu T, Wang C, Zhang Q, Liu F, et al. PAK1mediated MORC2 phosphorylation promotes gastric tumorigenesis. Oncotarget. 2015;6:9877-86.

21. Zhang Q, Song Y, Chen W, Wang X, Miao Z, Cao L, et al. By recruiting HDAC1, MORC2 suppresses p21 Waf1/Cip1 in gastric cancer. Oncotarget. 2015;6:16461-70.

22. Papini N, Anastasia L, Tringali C, Dileo L, Carubelli I, Sampaolesi $\mathrm{M}$, et al. MmNEU3 sialidase over-expression in $\mathrm{C} 2 \mathrm{C} 12$ myoblasts delays differentiation and induces hypertrophic myotube formation. J Cell Biochem. 2012;113:2967-78.

23. Andres V, Walsh K. Myogenin expression, cell cycle withdrawal, and phenotypic differentiation are temporally separable events that precede cell fusion upon myogenesis. J Cell Biol. 1996;132: 657-66.

24. Khaidakov M, Lai KK, Roudachevski D, Sargsyan J, Goyne HE, Pai RK, et al. Gastric Proteins MUC5AC and TFF1 as Potential Diagnostic Markers of Colonic Sessile Serrated Adenomas/ Polyps. Am J Clin Pathol. 2016;146:530-7.

25. Johansen LM, Iwama A, Lodie TA, Sasaki K, Felsher DW, Golub TR, et al. c-Myc is a critical target for c/EBPalpha in granulopoiesis. Mol Cell Biol. 2001;21:3789-806.

26. Mancini A, El Bounkari O, Norrenbrock AF, Scherr M, Schaefer D, Eder M, et al. FMIP controls the adipocyte lineage commitment of $\mathrm{C} 2 \mathrm{C} 12$ cells by downmodulation of $\mathrm{C} / \mathrm{EBP}$ alpha. Oncogene. 2007;26:1020-7.

27. Fux C, Mitta B, Kramer BP, Fussenegger M. Dual-regulated expression of C/EBP-alpha and BMP-2 enables differential differentiation of $\mathrm{C} 2 \mathrm{C} 12$ cells into adipocytes and osteoblasts. Nucleic Acids Res. 2004;32:e1.

28. Ding QS, Zhang L, Wang BC, Zeng Z, Zou XQ, Cao PB, et al. Aberrant high expression level of MORC2 is a common character in multiple cancers. Hum Pathol. 2018;76:58-67.

29. Pan Z, Ding Q, Guo Q, Guo Y, Wu L, Wu L, et al. MORC2, a novel oncogene, is upregulated in liver cancer and contributes to proliferation, metastasis and chemoresistance. Int $\mathrm{J}$ Oncol. 2018;53:59-72.

30. Schottmann G, Wagner C, Seifert F, Stenzel W, Schuelke M. MORC2 mutation causes severe spinal muscular atrophy-phenotype, cerebellar atrophy, and diaphragmatic paralysis. Brain. 2016;139(Pt 12):e70.

31. Zhang FL, Cao JL, Xie HY, Sun R, Yang LF, Shao ZM, et al. Cancer-associated MORC2-mutant M276I regulates an hnRNPMmediated CD44 splicing switch to promote invasion and metastasis in triple-negative breast cancer. Cancer Res. 2018; 78:5780-92.

32. Sevilla T, Lupo V, Martinez-Rubio D, Sancho P, Sivera R, Chumillas MJ, et al. Mutations in the MORC2 gene cause axonal Charcot-Marie-Tooth disease. Brain. 2016;139(Pt 1):62-72.

33. Yeamans C, Wang D, Paz-Priel I, Torbett BE, Tenen DG, Friedman AD. C/EBPalpha binds and activates the PU.1 distal enhancer to induce monocyte lineage commitment. Blood. 2007;110:3136-42.

34. Hadaschik D, Hinterkeuser K, Oldak M, Pfister HJ, Smola-Hess S. The Papillomavirus E2 protein binds to and synergizes with $\mathrm{C} /$ EBP factors involved in keratinocyte differentiation. J Virol. 2003;77:5253-65.

35. Xu X, Vatsyayan J, Gao C, Bakkenist CJ, Hu J. HDAC2 promotes eIF4E sumoylation and activates mRNA translation gene specifically. J Biol Chem. 2010;285:18139-43. 